\title{
THE EFFECTIVENESS OF A COUNSELING TRAINING PROGRAM FOR TEACHERS IN MODIFYING THE BEHAVIOR OF PUPILS LEARNING DISABILITIES IN THE THIRD GRADE
}

\author{
Asmaa Al Aazmy, Nadia Tazi and Mansoor Sayyah \\ Arabian Gulf University,Bahrain
}

\begin{abstract}
The current study aimed to examine the effectiveness of a counseling program for the female teachers to modify the unacceptable behaviors of the students with learning disabilities using the semi-experimental design. the ultimate study sample consisted of (12) female grade three teachers, in addition to (35) male and female grade three students was showed that the most common unacceptable behaviors among grade three students with learning disabilities include: talking with friends during the lesson, speaking in the class without the teacher permission, interrupting other students while speaking, not following the teacher's instructions and throwing wastes in the class , There are statistical differences between the pre- testing and the post-testing of the level of the unacceptable behaviors among the experimental group, in favor of the post - testing. There are no statistical differences between the pre -testing and the post-testing of the level of the unacceptable behaviors among the control group. There are statistical differences in the post- testing of the level of the unacceptable behaviors between the experimental group and the control group, in favor of the experimental group. There are no statistical differences in the post-testing of the level of the unacceptable behaviors between the male students and the female students of the experimental group , There are no statistical differences between the post -testing and the follow up -testing of the level of the unacceptable behaviors among the experimental group.
\end{abstract}

Keywords: Counseling Training Program,Behavioral Problems,Learning Disabilities

\section{Introduction}

The school is a social institution after the family in terms of impact on the child breeding and caring, for its important educational process, and refining the minds of children, since receiving them at an early age. In doing so, the school is considered the first station to deal with the children directly after the family, which placing it in an educational and instructional strategic location, from which it can monitor all educational and behavioral aspects of the pupils, and can discover their abilities, and negative and positive sides in their character, and then guide their behaviors in the desired direction.

Students who have difficulty fulfilling the requirements of school or home, and do not make an effort to improve their academic abilities, often face a lot of social and behavioral problems with others. Abu Alia and Melhem (1998) suggests that primary school pupils who fail academically, show different forms of behavioral problems, including the inability to pay attention or concentration, and deficits in motor skills. Khulaifi (1994) also explained that the most important behavioral problems among those pupils, are neglecting homework, and disorderly behavior, and that these problems increases with age and schooling, and were more clear among boys than girls, and the underachievers than the superior, and the older school grades than the lower ones.

The learning disabled students is one of the special education categories, and who suffer from behavioral problems associated with learning disabilities, and they suffer academic difficulties, which may badly effect their academic achievement and their relationships with their peers and the community and their image of themselves, so they need training programs that pay special attention to them in terms of dealing with their 
behaviors and adjust them, in order to help them adapt with the community and the school, so the primary task of the teacher is to help the student to acquire different types of behavior which prepare him to be a good and happy citizen who is capable of participating in the production in his society.

A lot of students with learning disabilities suffer from some behavioral problems. Being with normal intelligence or above average, and possibly higher, these students with LD are more aware of his failure in the school, they can also be more sensing to the implications of his academic failure on their homes. This consciousness leads to many kinds of psychological tensions and frustrations that create increasing bad emotional impact due to his inability to improve his academic level at school, and the implications of this situation in both school and home (Zayat, 2006).

\section{Research Problem:}

Many educators and scholars in the field of education noted that the behavioral problems of students negatively affect their academic achievement and the nature of the relationship between them and their peers, as well as their relationships with their teachers and members of his family.

It is often clear to the teacher that students with learning disabilities suffer from behavioral and social problems. Teachers themselves may be the target of these pupils aggression. Teachers also find out that those pupils do not comply with the different school rules and demands. Sometimes teachers note that some students are unusually quiet, or withdraw from social situations and interactions, or do not have friends (Abdullah, 2006).

\section{Research Questions:}

What are the unacceptable most frequent behaviors among students with learning disabilities in the third grade?

Is there any statistically significant differences between the pre and post testing of the unacceptable behaviors level among the experimental group?

Is there any statistically significant differences between the pre and post testing of the unacceptable behaviors level among the control group?

Is there any statistically significant differences between the experimental group and the control group in the post testing of the unacceptable behaviors level?

Is there any statistically significant differences between the males and females of the experimental group in the unacceptable behaviors level?

Is there any statistically significant differences between the post and the follow-up testing of the unacceptable behaviors level among the experimental group?

\section{Research objectives:}

To identify the most repeated behavioral problems among the third grade primary pupils.

To develop a counseling training program that aim to guide and train regular classroom teachers on how to deal with behavioral problems of students with learning disabilities, and to verify its effectiveness.

To raise the teachers awareness of the importance of adjusting the unacceptable behaviors among students with learning disabilities in the regular class, and train them on some behavior modification techniques.

\section{The Research Significance}

The results of the current research may be useful for those who work in the field of education, and may help them in how to deal with pupils with behavioral problems in order to improve their behavior, and may help to avoid unacceptable behaviors in the classroom. 
The current research highlights the importance of preventive interventions in controlling the student's behavior in the classroom, through helping the teacher to know and understand some of the methods and strategies to face any unacceptable behavior by a pupil.

The current research changes the intervention programs orientation from the pupil to be counseling programs for the teacher.

\section{Theoretical Framework:}

Despite the differing views on the concept of learning disabilities, there is consensus that problems of the individuals with learning disabilities are real problems and deserve appropriate educational intervention, as they pose a big problem for many people who suffer from them, as they face real challenges that are not confined to academic aspects, but these challenges extend to affect the social aspects of their lives as well.

There is no doubt that these problems create a need to guide this group of students. As MacMillan and Siperstein (2002) confirm that students with learning disabilities who display behavioral problems, are considered in urgent need of effective interventions because they face academic and behavior problems.

This chapter deals with the theoretical framework, through the following axes: the first axis presents the learning disabilities, the second axis presents behavior, the third axis presents counseling, in addition to the literature review related to the subject of study.

\section{Axis I: Learning Disabilities}

\section{The concept of learning disabilities:}

The field of learning disabilities, as any area, faces of the problem of the definition and the exact description of the patterns of different behavioral models for children with learning disabilities, and the ensuing confusion and differences in defining a clear concept of learning disabilities, or confine it to a specific area of study, resulting in moving many specialists and interested parents to claim for a specific definition of learning disabilities (Chalfant \& ding, 2003).

Historical development, through which the concept of learning disabilities has passed, has led to the emergence of a variety of different definitions, it addressed the lack of student 's ability to learn normally despite the availability of mental capacity necessary to learn, and the safety senses such as sight, hearing, and the availability of appropriate educational opportunities, In addition to the emotional balance, and the lack of economic constraints or social problems.

And it is obvious that the National Joint Committee on Learning Disabilities NJCLD definition in (1994) is the most accepted definitions in this area, which defines learning disabilities as: " a general term refers to a heterogeneous group of disorders, which expresses itself through significant function difficulties in the acquisition and use of the capabilities of listening, talking, reading, writing, Inference or mathematical abilities, which are endogenous disorders, and are supposed to be due to a defect in the central nervous system, and can occur during an individual 's life. It can also be accompanied with self - control problems, and the problems of cognition and social interaction, but these problems alone do not create learning disabilities. Although learning disabilities can simultaneously occur with some other disability conditions (such as: senses disabilities, intellectual disability, or substantial emotional disturbance), or with external influences (such as cultural differences or insufficient or inadequate teaching / learning), but they - learning disabilities - are not a result of these conditions or influences (Elison, 2001). 


\section{The concept of behavioral problems:}

Kauffman (1985) refers to the problem or disruptive behavior as: a kind of behavior seen unbearable by those with power in a culture. Kaufman adds that disruptive behavior is determined by a child's inability to formulate his behavior in the daily environment in a way that keeps him away from being blamed by others, and help him to get accepted by them. He believes that the difference between behave and troubled behavior is in degree and not in type, normal children do almost everything troubled children do, but not in the same circumstances or the same rate. Shouting, fighting and urinating.. etc. represent behavioral patterns that can be expected from both normal children and troubled children, but the circumstances and the rate and intensity of these behaviors among the troubled children are different from normal children.

\section{The relationship between behavioral problems and learning disabilities:}

Studies indicate that students with learning disabilities are more tending and more likelihood to utter unacceptable and rejection indicating words, and fail to respond to social initiatives by ordinary classmates, and in return these learning disabled students receive more verbal phrases to take into account the feelings of others and even more phrases that address competing more than ordinary children (Gable, R, et al, 1998)

\section{The second axis: behavior modification}

\section{Definition of behavior:}

Behavior is a phenomenon that human behavior scientists study, and there is no doubt that our definition of behavior has a dramatic impact on the strategies of measurement and treatment that we use. In general we can define behavior as all the actions and activities of the individual weather visible or not visible. Johnston and Pennypacker (1980) claims that the scientific definition of the behavior should take into account the interaction between the individual and the environment, which suggests that this process is of continuous interaction. Behavior is not a static thing, but it changes, which does not happen in isolation but in the environment. Johnston and Pennypacker define behavior as "that part of the interaction of the organism with his environment, through which the organism's movement or part of it can be explored in space and time, which results in a change to the measure in at least one aspect of the environment. This means that behavior is a phenomenon that is studied bythe science of human behavior, and means the interaction between the individual and his environment (Al - Khatib, 2001).

\section{The importance of behavior modification:}

Behavior modification is a learning method that includes the formation of new behavioral patterns, and curbs the unacceptable habits and responses, and promotes and strengthens acceptable responses, i.e. increasing acceptable behavior, the formation of new behavior to be learned, and weakening unacceptable behavior. The importance of behavior modification can be shown in the following points:

It works to train the student (or any person with a disorder) on the skills needed to deal successfully with different situations at home, school and the surrounding environment.

It increases the capacity of the student's interaction and social acceptance.

It helps to develop self - concept among students and increase their self confidence. It helps the student to overcome the symptoms and problems associated with the disorder through more self control, and the control of responses and increase the motivation and its insistence on completing the work, and increase its focus during the performance, so as to ensure its academic and social success (Al-Abadi, 2005).

Behavior modification strategies: 
Behavior modification approach is a therapeutic approach, emerged from the traditional behavioral school, led by Skinner. This approach depend on the principle of reward and punishment when the individual performs certain behavioral patterns, so acceptable behavioral patterns are rewarded, and the unwanted behavioral patterns are punished (Al-Zayat, 1998).

\section{The literature Review}

Previous studies are reviewed in two axes: studies on the behavioral characteristics of people with learning disabilities, and studies of programs and strategies used in decreasing and modifying unacceptable behavior.

The first axis: studies on the behavioral characteristics of people with learning disabilities

Almakanin, Al-Abdellat \& Alnagadat (2014) aimed to identify behavioral problems among students with learning disabilities and their relationship to social efficient from the teachers and peers points of view. The study sample consisted of (135) male and female students with learning disabilities enrolled in the resources rooms in the schools of the Southern Region directorates, in Jordan. The study used a measure of two forms, the first form is for teachers and the second for ordinary students to judge the behavioral problems among students with learning disabilities, the study also used Walker - McConnell Social efficiency and School adjustment measure. Results of the study showed that the behavioral problems prevailed among students with learning disabilities, according to teachers' estimates are: problems associated to the dimension of ADHD, followed by the problems associated with the dimension of the withdrawal, then the problems associated with the dimension of stubbornness, then the problems associated with the dimension of aggression, and the least prevailed behavioral problems are associated with the dimension of dependence. While the peers estimates of the most prevailed behavioral problems among students with learning disabilities are associated with the dimension of $\mathrm{ADHD}$, followed by the problems associated with the dimension of the stubbornness, then the problems associated with the dimension of dependence, then the problems associated with the dimension of withdrawal, and the least prevailed behavioral problems are associated with the dimension of aggression.

Huwaidi and Yamani (2007) study aimed to identify unacceptable behavior from the point of view of teachers among the third and sixth grades students of public elementary schools. The number of respondents (249) teachers teaching these two grades in 19 elementary schools in four governorates in Bahrain. The study used a questionnaire consisted of (54) items, each of which represents unacceptable behavior, and cover four behavioral areas. The most important findings indicate that the unacceptable behaviors in common among students are related to those directed towards grade pupils, followed by those directed to class property, while the least common were those directed towards the teacher, it turns out that unacceptable behavior is common among male students more than females, while there is no significant differences between the students of the third and sixth grades.

\section{The second axis: studies of the programs and strategies to reduce and modify unacceptable behavior}

Jameel's study (2005) aimed to verify the effectiveness of a counseling program to modify teachers' attitudes towards children with learning disabilities, the study sample consisted of (60) male and female teachers of primary school in Alexandrian. The study findings showed the following: There are significant differences between the experimental and control groups after applying the counseling Program for the experimental group. There are significant differences between the pre and post testing of the experimental group in favor of the post testing., and there are no statistically significant differences between mean scores of the experimental group on attitudes scale directly after the application of the program and after two months of follow-up.

Sutherland and Wehby (2001) conducted a study that aimed to evaluate the impact of teachers' behaviors in teaching such as (variety of teaching methods and classroom activities to achieve academic goals, and providing opportunities for students to respond to academic tasks, and promoting correct responses) on the behavior of pupils with behavioral and emotional disorders. the study sample consisted of (20) teachers working in kindergarten through eighth grade, divided into two groups; (10) teachers in the experimental group, and (10) teachers in the control group. The sample also included (216) pupils from 20 school classes, of whom (112) pupils with behavioral disorders, and were divided into experimental and control groups, and (48) learning disabled pupils, and were divided into 20 in the experimental group 
and (28) in the control group, and (20) students were classified as having mental retardation, and were divided into (14) in the experimental group, and (6) in the control group. The age range of the respondents is ranging from (5-15) years, and they all have behavioral problems in the classroom.

\section{We conclude the following:}

The possibility of reducing or limiting unacceptable behaviors, and through the use of a set of the strategies that fit the nature of the problematic behavior, and this is sought by the current study, by focusing on a group of the strategies that have proven their effectiveness through previous studies, and applied with these pupils to reduce their unacceptable behaviors.

The unacceptable behaviors can also be reduced by the use of behavior modification mechanisms, as the good behavior game, verbal reinforcing and token economy and the cost of the response, as well as reinforcing incentives, and varying teaching methods and classroom activities to achieve academic goals, and providing opportunities for students to respond to academic tasks, and promoting correct responses. And that's what the current study tried to work with, by focusing on a range of behavior modification techniques such as behavioral contract, the cost of the response, and behavior formation through a counseling program.

There is no doubt that the results of previous studies have helped in shaping the problem of the current study and formulating it in the light of the nature of behavioral problems of the people with learning disabilities, that are different from those of the ordinary, as well as to proposing a program that includes a range of behavior modification mechanisms that proved effective in reducing the unacceptable behaviors, as illustrated by the results of previous studies, and thus the current research methodology was determined, to work to reduce the unacceptable behaviors, and the tools necessary to determine the most repeated problems.

In addition, the results of previous studies have contributed to identify current research variables, and then the theoretical framework introduced in the light of those variables.

Finally, the current research results were discussed in the light of the findings to him the results of previous studies, according to its relation tothe current research results.

\section{Research procedures:}

- Research Methodology: The research used the quasi experimental methodology, which focuses on identifying the effect of an independent variable on a dependent one. In this study, the effect of a counseling program for teachers on modifying the learning disabled students' unwanted behavior is verified.

- $\quad$ Research variables: The research includes two types of variables:

A. Independent variable: A suggested counseling program for female teachers.

B. The dependent variable: Learning disabled students' unwanted behaviors.

- The research sample: The research sample consisted of two main groups, the teachers' group (n $=12$ ), which and was distributed into an experimental group $(n=6)$ and a control group $(n=6)$, and the primary school students' group $(n=35)$, which was also distributed into two subgroups; the experimental group $(\mathrm{n}=19)$, of which (10) males, and (9) females, and the control group (16), of which (6) males, and (10) females.

- The research tools: The current research used a number of tools, they are divided into two sections:

A. First: diagnosis tools of learning disabilities:

- IQ test: Raven Progressive Matrices Test (Arabized by: Awadh, 1999) 
- $\quad$ Learning Disabilities Diagnostic Rating Scale (LDDRS) (El-zayat, 2007).

B. Second: The research tools:

- The training program for class female teachers (prepared by the researcher), which consists of 12 sessions, consisting of five mechanisms; behavioral contracts, cost of response, behavior formation, excessive correction and exclusion from positive reinforcement.

- The Unwanted Behaviors Questionnaire (developed by: Huwaidi and Yamani, 2007).

- $\quad$ The Unwanted Behaviors checklist (prepared by the researcher).

\section{Research results:}

The results of the first question: The unwanted behaviors among the LD students are as follows:talking with colleagues during the lesson came first, speaking in the class without the teacher's permission came second, interrupting other colleagues while speaking came third, not following the teacher's instruction came fourth, throwing the dirt in the class came fifth.

The results of the second question: There are statistical differences between the pre testing and the post testing of the experimental group, on theunwanted behaviors questionnaire, and the unwanted behaviors checklist, in favor of the pre testing, which means that the unwanted behaviors decreased after the counseling program.

The results of the third question: There are no statistical differences between the pre testing and the post testing of the control group, on the unwanted behaviors questionnaire, and the unwanted behaviors checklist.

The results of the fourth question: There are statistical differences between the experimental and the control group in the post testing on the unwanted behaviors questionnaire. That the unwanted behaviors are less among the experimental group more than the control group in the post testing, and the unwanted behaviors checklist.

The results of the fifth question: There are no statistical differences between the experimental group males and females, in the post testing, on the unwanted behaviors questionnaire, and the unwanted behaviors checklist.

The results of the sixth question: There are no statistical differences between the post testing and the follow up testing of the experimental groupon the unwanted behaviors questionnaire, and the unwanted behaviors checklist.

\section{Research recommendations:}

Adoptingthe behavior formation and the behavior contract in lessening the unwanted behaviors among the LD students in primary schools.

Developing counseling programs for the teachers and parents of LD students, to raise their awareness of LD.

Developing behavioral, intervention programs, in the light of the LD students' characteristics.

Training teachers on the behavior modification techniques, to reduce the students unwanted behaviors.

\section{Future research:}

Conducting studies similar to this one, on different samples, with different age ranges, and different environments.

Conducting a comparative study to compare the efficiency of the behavior contract technique and the behavior formation technique in modifying the students' unwanted behaviors in the class .

Conducting a study to find out the prevalence of behavioral problems among LD students in the primary school. 
Asmaa Al Aazmy, Nadia Tazi and Mansoor Sayyah/The Effectiveness of a Counseling Training Program for Teachers in Modifying the Behavior of Pupils Learning Disabilities in the Third Grade

Conducting a study to find out the effect of behavioral problems on other educational phases among LD students.

\section{References}

Abadi, M., 2005, Contemporary strategies for the class administration and organization (Oman, Seeb: Aldhamra Library for Publishing and distribution).

Abdullah, A., 2006, Some cognitive variables for kindergarten children with deficits in the academic skills as an indicator of learning disabilities. A paper presented in the International Conference on Learning Disabilities, Riyadh, Kingdom of Saudi Arabia, from 28 October -2 November, 1427, 19-22 / 11/2006.

Abu Alia, M. and Melhem, A. Q., 1998, Effectiveness of the Resource Room Program in reducing behavioral problems among a sample of female students with academic learning disabilities from the third and fourth grades of Amman City Schools. Muatah Journal for Research and Studies, 13 (6), 11 - 39.

Aldhaher, Q., 2004, Behavior Modification (2 ${ }^{\text {nd }}$ Ed.) (Amman: Dar Wael for printing and publishing).

Al-Khatib, J. (2001). Modification of the human behavior (Kuwait: Alfalah Publishing And distribution Library).

Almakaneen, H., Abdullat, B. and Nagadat, H., 2014, behavioral Problems among Students with difficulties learning and their relationship to Social efficiency from the teachers and peers point of View. Journal of Jordan at Science Education, 10 (4). 503 - 516.

Al-Zayat, F.M., 1998, learning disabilities the theoretical and the diagnostic and therapeutic foundations. (Cairo: Publishing House of the universities).

Al-Zayat, F. M., 2006, Remedial teaching mechanisms for people with attention deficit hyperactivity disorder. International Conference on Learning Disabilities, Riyadh, Kingdom of Saudi Arabia, from 28 October -2 November 1427, 19-22 / $11 / 2006$.

Chalfant, J. and Ding, F., 2003, Approach to operationalizing An the definition of learning Disabilities . Learning disabilities Journal, 9 (4), 34-49.

Cooper, JO, Heron, TE, and Heward, W.L., 1987, Behavior analysis All Applied (Columbus: Merrill Publication Company).

Craighead, WE, Kazdin, AE. and Mahoney, MJ., 1981, Modification Behavior: Principles, issues, and applications (Boston: Houghton Mifflin Company).

Elison, M., 2001, Behavioral Variables in two learning disabilities Subtypes. Journal of Learning Disabilities, 28,35 - 46.

Huwaidi, M. and Yamani, S., 2007, unacceptable behaviors from the primary stage teachers and students point of view in the Kingdom of Bahrain. Journal of Educational and Psychological Sciences, 8 (1) 13 - 44.

Johnston, J. \& Pennypacker, H., 1980, Strategies and tactics of human behavioral research (Mahwah, NJ: Lawrence Erlbaum).

Kavale, K.A and Forness, S.R., 1996, Social skill deficits and learning disabilities: A meta-analysis. Journal of Learning Disabilities, 29 (3), 226-237.

Kazdin, A.E., 1978, Behavior modification of History: Experimental foundations of contemporary research. (Baltimore: University Park Press).

MacMillan, D.L, and Siperstein, G.N., 2002, Learning disabilities as operationally defined by schools. In: R. Bradley with In, L. Danielson, \& D. Hallahan (Eds.), Identification of Learning Disabilities: Research to Practice. (Mahwah NJ: Erlbaum), pp. 520-586. 
Sutherland, K. S. and Wehby, J. H., 2001, Exploring the relationship between increased opportunities to respond to academic requests and the academic and behavioral outcomes of students with EBD. Special and Remedial Education, 22 , 113-121. 